95\% CI: 1.5 to 60.9$)$ respectively having been adjusted by age group and working activity.

Discussion Miners appear to be more susceptible of developing IKF rather than other manufacturing workers. Further research is needed to explain the role of specific occupational exposures in kidney impairment among miners.

\section{6d USABILITY TESTING FOR ERGONOMIC CRITERIA MATRIX: CASE STUDY OF A DEEP MINING COOLING VEST}

V Ngô, S Nadeau, S Hallé*. Ecole de technologie supérieure, Montreal, Canada

\subsection{6/oemed-2018-ICOHabstracts.699}

Introduction Deep mining and ultra-deep mining (UDM) push the boundaries of what is considered tolerable for workers in hot and humid environments. Since ventilation is costly for mining companies, a novel personal protective equipment (PPE), a cooling vest, is a possible means to safeguard the health and safety of miners. Such a PPE must meet both their needs and expectations. The objective of this study was to build a matrix of ergonomic criteria that would help define the base on which a cooling vest would be developed for deep and UDM.

Methods First, a literature review was conducted on the constraints and requirements that miners are subjected to in deep mining conditions. Then, a field study was conducted in a mine in Abitibi Témiscamingue, Canada. A convenience sample of 20 participants was used to collect information such as height, weight, PPE worn as well as concerns as to the use of a cooling vest. The information collected was then interpreted to generate the matrix of ergonomic criteria suitable for an UDM environment.

Results All participants agreed that a cooling vest would help alleviate the risk of a heat stroke, as well as improve their well-being during work. The main concerns of minors relate to the weight, the comfort and ease of movement. Additional criteria such as design aesthetics, maintenance and conformity to laws, regulations and standard have been added to the matrix. The resulting matrix contains 16 criteria, seven of which are centred on the user and nine on the design of the cooling vest.

Discussion We are hopeful the matrix can be validated and that it will be possible to broaden its use to apply it, for instance, in the development of cooling vests for other hot and humid work environments such as foundries and certain construction projects.

\section{6e GOOD PRACTICE GUIDANCE ON OCCUPATIONAL HEALTH RISK ASSESSMENT}

CJ Badenhorst. Anglo American plc., Johannesburg, South Africa

10.1136/oemed-2018-ICOHabstracts.700

In 2009 the International Council on Mining and Metals (ICMM) developed the Good Practice Guidance on Occupational Health Risk Assessment to help site practitioners assess and address the risks posed by health hazards in the mining and metals sector. It provided those practitioners with the information they needed to assess the health and well-being of employees and contractors. In 2016 a review was undertaken to bring the text and advice up to date with changes in the field of occupational health risk assessment and align this document with the terminology and approaches proposed in ICMM documentation published since the first edition, principally the concept of material unwanted events (MUEs) and the management of those through the use of critical controls. The guide identifies the occupational health impacts of mining and metals processing, outlines good practices in the identification of hazards and exposed workers, assists practitioners in estimating exposure levels and assessing the effectiveness of controls and explains the importance of quality analysis and reporting. Healthy workers are essential to the success of mining and metals companies, and ICMM company members are driven in their protection of the health and well-being of both workers and local communities by the ICMM's Sustainable Development Principle 5: 'Pursue continual improvement in health and Safety performance with the ultimate goal of zero harm'. Occupational health risk assessment is the foundation of any occupational health programme and will determine the effectiveness of the programme. It is the intention of the ICMM that this publication provides a practical tool to assist companies in protecting the health and well-being of their workforce.

\section{$1636 f$ VISION ZERO - THE GLOBAL FUTURE TO PREVENT ACCIDENTS AND DISEASES IN MINING}

$\mathrm{H}$ Ehnes. International Section of the ISSA Mining on Prevention in the Mining Industry, Bochum, Germany

\subsection{6/oemed-2018-ICOHabstracts.701}

The Singapore World Congress on Safety \& Health at Work 2017 truly marked a milestone in prevention. The International Social Security Association (ISSA) launched the Global VISION ZERO Prevention Strategy. As a leading organisation representing more than 320 members in over 150 countries, the ISSA enters a new level of commitment towards 'zero harm' and presents a toolset called the 'Seven Golden Rules' which delivers hands-on solutions for businesses. The approach gives systematic answers to companies worldwide on how to improve safety and health at work while offering a harmonised, proven toolset for managers.

The Golden Rules span the areas

Golden Rule 1: Take leadership - demonstrate commitment

Golden Rule 2: Identify hazards - control risks

Golden Rule 3: Define targets - develop programmes

Golden Rule 4: Ensure a safe and healthy system - be wellorganised

Golden Rule 5: Ensure safety and health in machines, equipment and workplaces

Golden Rule 6: Improve qualifications - develop competence

Golden Rule 7: Invest in people - motivate by participation

The presentation will discuss the development of the 'Seven Golden Rules' by ISSA's Prevention Section for the Mining Industry and gives insight into the implementation in Germany, where the German social accident insurance institution for the raw materials and chemical industry - BG RCI introduced it for 35000 companies.

It will explain the VISION ZERO mindset and experience both internationally and in Germany, and demonstrate what aims, measures and tools have been derived. Furthermore options for cooperation will be discussed. 